DOI: $10.1515 / \mathrm{abcsj}-2017-0008$

\title{
What Big Teeth She Has
}

\author{
ELLA MCLENNAN
}

\begin{abstract}
Myra Hindley is one of the most notorious female murderers in the world. This poem explores the ways in which Hindley has been, and continues to be mythologised by society. It examines the mythical women that have been compared to her, and attempts to demonstrate how dangerous it is to compare real people to fictional characters. The poem discusses how the press depicts murderers and the affect this has on the world. Using examples such as Dracula, the poem also reflects on how facts lose truth over time, and how many stories about real people have become mythologised whether this was intentional or not.
\end{abstract}

Keywords: Myra Hindley; Moors Murders; mythology; murder; crime; dehumanisation; sexism; victim

\section{Clytemnestra}

The plotting Queen, an adopter of the masculine role of adulterer.

Transgressive like the sadomasochistic tendencies, like the relationships she engaged in incarcerated.

The weapon drips.

The bath water is turning red.

Clytemnestra stands

over Agamemnon's body

with pride,

happily

like her

trophy photographs. 


\section{Medea}

A sorceress, and

worshipper of Hecate, the Goddess of witchcraft.

A destroyer of family,

like the 1960s social change,

like the breakdown of tradition,

like the brutality.

They cry from inside

to escape their mother

when she fully defied

any maternal instinct

with infanticide.

Their pleas grow silent.

\section{Medusa}

The terrible woman, sinister, unfeminine.

Phallic serpents instead of long hair, and viridescent skin.

Scaled, and horrifying to behold.

Medusa's stony gaze,

like hers in the iconic mug shot:

hostile, and unyielding in monochrome.

There is no grey area.

As if to understand,

as if to attempt to understand,

is to condone.

The Devil

's Wife

The Devil

's Disciples

Marlowe's chief lord,

and regent of perpetual night. 
Shape shifting to become a serpent

of Eden,

of one of many in Medusa's twisted crown.

Rejecting the word of God,

like her, an apostate,

like her, turning values upside down.

She came to believe,

as he did before her,

that Christianity is as Nietzsche deems:

a fatal and seductive lie.

The Devil is a dweller of the underworld and hell,

and "at last, Myra is where she belongs..."

Myra

A personification of the myths.

Violator of gender norms,

of human norms.

A Frankenstein's monster

amalgamation of fiction.

That holy shape becomes a devil best.

A Siren for children, a wolf in grandmother's clothes.

What a broad build she has,

what brassy blonde hair.

She is paradoxically

propelled to supernatural status,

whilst plummeted to a human subspecies.

Neither and either.

Nothing and both.

But she was not a witch,

nor a queen,

nor a mother.

The one more hated

because she is a she? 
Is he, whilst imprisoned, the one more free?

Is he cloaked in his insanity?

Protesting her degree of culpability:

I grew fat on a diet of his Hitler, de Sade,

Dostoyevsky.

I was a blind disciple

of King rat,

of the two headed boy.

I did that, but I did not do that.

I am infatuated in my youth,

I am his mirror,

with eyes so dilated I have become his pupil.

Branded a Clytemnestra, Medea, Medusa, and the Devil.

These are transcendental figures

not of Earth

used to describe earthly events.

These are labels which do not bother to explain,

but drip with infamy.

Sensationalised heavily.

As murderers are male in history, by default, usually

this meant the rarity of this instance generated a pure, new hatred, of women who are murderers, misogynistic, and scapegoating.

But, could it be that behind every "great" man is a

There are those exemplary of factual notoriety turned myth: 
Vlad Ţepeş

Or Dracula,

The Impaler.

Elizabeth Bathory

Or The Blood Countess.

Their victims uncounted for,

yet both feature heavily

in pop culture, in folk lore.

Stripped of their humanity,

and sculpted instead as caricatures.

Fanciful imaginations,

word of mouth,

and fables handed down

means their lives are fictionalised.

The stories altered over centuries,

and incorrectly memorised.

Nicknames given too:

Yorkshire Ripper,

Night Stalker,

Werewolf of Wysteria.

Milwaukee Cannibal,

Killer Clown,

Dr Death.

The Moors Murderers.

Catchy.

Alliterative.

And yet, these eerie

and inhuman titles

are aliases which

globally popularise them,

further them from mankind,

create celebrity status,

and leave us blind. 
Are articles, and literatures which alter truth on subjects such as these

harmful?

Obscene?

Insightful?

Necessary?

When so called true crime, often fabricated, poorly written, sees an era of intense popularity do readers realise what they read?

Black and white.

Angels and devils.

Lambs and lions.

Salvation and damnation.

How can it not be?

How can it be?

The language used for situations like these is that of oppositional binaries.

The pedestalled

and the condemned.

The unthinkable,

and the infinitely natural.

Juxtaposed in photographs

on tabloid front pages

were, and sometimes still are, the devils and the angels.

Many texts use archetypes

though not all victims were shown

in the wholly angelic light.

Seen as less pure

in some way. 
Perhaps for the link

of homosexuality

to monstrosity.

The assumption of

sexual awareness

constructed a murdered teenager

to a willing adult

despite the abhorrent unfairness.

In her case,

with her face and name so ingrained into society,

the answers,

the details

will remain unknown.

Gone before her divulgence,

gone before it was demonstrated

she had a ribbon of empathy

for the lives affected.

In the traumatising tape recording,

black and white proof,

and the power of persuasion

an extent of complicity is clear,

despite her pleading not guilty.

Feigning needing help,

acting as the lure,

gaining trust.

Myra.

Sister. Daughter. Murderer. Liar.

But still human.
A body never found
means the book is never closed.
For the public, whether grieving, compassionate, 
or made sightless by loathing

the history is forbidden from

dissipating

into oblivion.

Instead it is remembered

down to minute detail,

accurate or

not.

Regurgitate the churnalism, she can be your villain, your flashing eyed Medusa for eternity.

Repeat dehumanisation,

repeat the invented hierarchy of victims.

Repeat,

repeat,

repeat,

until her name feels heavy in your mouth

when you say it out loud.

What a broad build she has!

What brassy blonde hair,

all the better to

place the emphasis on her appearance,

demonise the working class,

romanticise the landscape.

Fear monger,

mythologise,

make the weak comparisons, and

distance,

distance,

distance.

The dehumanisation of a murderer 
is understandable.

But in turn, it

dehumanises their victims.

When roughly every six months

a person was torn from existence

it must be remembered that

to lessen the reality

of her personhood

is to lessen the reality

of her crimes.

There is no life

unworthy of life.

There is no black,

there is no white. 